\title{
KINEMATICS OF EXPERIMENTALLY PRODUCED DEFORMATION BANDS IN STIBNITE
}

\author{
DAVID R. MCQUEEN *, WILLIAM C. KELLY and BRUCE R. CLARK ** \\ Department of Geology and Mineralogy, The University of Michigan, Ann Arbor, \\ Michigan 48109 (U.S.A.)
}

(Received November 29, 1979)

\begin{abstract}
McQueen, D.R., Kelly, W.C. and Clark, B.R., 1980. Kinematics of experimentally produced deformation bands in stibnite. In: W.M. Schwerdtner, P.J. Hudleston and J.M. Dixon (Editors), Analytical Studies in Structural Geology. Tectonophysics, 66: 55-81.
\end{abstract}

Using videotape techniques, we have observed the kinematic development of a variety of microstructures during experimental deformation of single crystals of stibnite $\left(\mathrm{Sb}_{2} \mathrm{~S}_{3}\right)$. The crystals were deformed by flexure or uniaxial compression at room $P$ - $T$ conditions in a small strain device attached to the stage of a reflecting microscope. In more than 50 experimental runs, the primary microstructures produced in stibnite were deformation bands, not deformation twins as often reported in the literature. Translation gliding along (010) [001] results in visible slipbands and produces two basic types of deformation bands, each with a variety of subtypes. Kink bands form with $\phi$ (angle of internal rotation) $\cong 70^{\circ}$ and perpendicular bands develop with $\phi \cong 90^{\circ}$. Other optical deformation features seen forming were: breccia fragments, bent and opened cleavages, and microfolds.

Four stages could be seen in the kinematic development of deformation bands. During initiation, bands form by nearly instantaneous propagation of a narrow bent zone across the crystal. During later migration, the bands widen at a rate invariably slower than the rate of initiation. Termination of bands occurs when growth is impeded by intersections with grain boundaries or other deformation features. During late modification, previously formed bands with straight boundaries are sheared, bent, and compressed. Unconfined crystals tend to form kinks, whereas the perpendicular bands formed in samples confined in relatively rigid plastic. Naturally deformed stibnites show the same features. Television photomicroscopy has great potential for studying microstructures during deformation.

\section{INTRODUCTION}

In the last three decades, there has been increased research in geology and engineering on the mechanics by which crystalline materials deform. An important microstructure, which has been recognized since the nineteenth

* Present address: U.S. Geological Survey, MS 920, Reston, VA 22092 (U.S.A.)

** Present address: Leighton and Associates, 17975 Sky Park Circle, Irvine, CA 92714 (U.S.A.) 
century and recently has come to the forefront, is the kink band. Following the usage of Hobbs et al. (1976, pp. 98-99) a kink band will be considered a subset of a more general microstructural grouping, the deformation band. Zones of strain within a crystal, appearing as sharp deflections of the structure, are termed deformation bands and are caused by stresses activating a complex translation-glide mechanism. Deformation bands have been analyzed in structural studies of both rocks and minerals because of their potential usefulness as stress direction indicators. The sulfides, in particular, are potentially significant in tectonic investigations because of their greater sensitivity to stress in lower $P-T$ environments than are the silicates (Clark and Kelly, 1976; Clark et al., 1977).

Many of the most exciting questions concerning the initiation and migration of deformation bands can only be addressed by examining the kinematics of their development. For example, where within a crystal does deformation banding initiate? How do deformation bands propagate in minerals? How does the geometry of this microstructure vary as strain increases? During its formation, in what way does a deformation band interact with: (1) other microstructures; (2) fractures; (3) grain boundaries; and (4) surface imperfections? To answer these queries, a special technique of television photomicroscopy was employed to record the results of real-time strain experiments.

Stibnite was chosen as an experimental material not only because of the high ductility required by our experimental design, but also due to the presence of enigmatic microstructures. Unique wedge-shaped features attributed to deformation have been noted in stibnite and have been called twins by several investigators. Ramdohr $(1969, \mathrm{p} .695)$ assumed that the texture of naturally deformed stibnite results, in part*, from "pressure twins". Cameron (1961, p. 65) describes this same type of microstructure in terms of glide-twinning produced by mechanical deformation. In the context of current terminology (see Clark and Kelly, 1976, pp. 51-53) and our present study, the "pressure twin" terminology should be abandoned. The major deformation features in stibnite are deformation bands, rather than any type of twin, as will be demonstrated. Early in our research the wedge-shaped features were noted to be analogous to documented kink bands in deformed galena and pyrrhotite.

PREVIOUS RESEARCH

Deformation bands have been recognized in minerals for decades. They have been referred to as kinks (Mitgge, 1898, p. 78; Stanton, 1972, p. 279), mechanical twins (glide twins or translation twins) (Cameron, 1961, pp. 64-

\footnotetext{
* There is a confusion of translation (from the German) or content in Ramdohr's association of the "crumpled lamellar texture" in stibnite with translation (p. 57) and then with twinning (p. 695).
} 
65), pressure twins (Ramdohr, 1969, p. 695), pressure-corrugated lamellae (Ramdohr, 1969, p. 59), or simply "regions joined at arbitrary and variable angles" by Lehman in 1885 (Klassen-Neklyudova, 1964, p. 116). Mugge's (1898) work entitled "On translation and related phenomena in crystals" provides a remarkably current listing of slip systems for a score of minerals (including stibnite), along with descriptions of various deformation band geometries.

Deformation bands have long been of interest to metallurgists as well, due to their common occurrence in metals. Orowan (1942) first described kinking by noting odd deflections in cadmium metal wires during tension and compression experiments. He considered this phenomenon to be a new deformation mechanism in metals. Hess and Barrett (1949) demonstrated correctly that kinks were a type of deformation band whose deformation mechanism is translation (basal) gliding (p. 599), and not a new deformation mechanism. They were the first to systematically apply dislocation theory to kinks and to study their initiation and growth in metals. The "unkinking" of a zinc rod, by application of tensile stresses, is reported by Gilman (1954). Reed-Hill $(1973$, p. 635$)$ cites the production of kinks as an accommodation to structural distortions produced by deformation twins.

Deformation bands are very common in silicates and sulfides. Since these mineral classes are commonly found in tectonites, the character and orientation of their deformation bands have been studied as direct indicators of the temperature-pressure conditions and orientation of stresses at the time of deformation. Kink-band boundaries have been shown to form at high angles to maximum compressive stresses (Paterson and Weiss, 1966; Salmon et al., 1974). In addition, previous research has explored the: (1) threshold stress conditions needed for kink-band formation in different minerals; (2) kinkband geometry (Starkey, 1968); and (3) crystallographic planes along which translation glide is activated during kink-band formation (Etheridge et al., 1973; Clark and Kelly, 1976).

The only previous study of the kinematics of deformation bands in crystals, to our knowledge, is that of Klassen-Neklyudova (1964, p. 134135). Using high-speed cinematography, shock-induced kink-band formation in single crystals of CsI and naphthalene was filmed under transmitted polarized light. The observations from that study of kink-band initiation and rates of formation will be compared to ours in the discussion section.

Kink bands also occur in deformed rocks having a highly anisotropic foliation (Weiss, 1972, plates 112A-116). Many of the features noted in mineral deformation bands have an analogy in kink-folded rocks. Weiss (1969) used paper card decks to model the kinking process in highly foliated rocks. Paterson and Weiss (1966) developed a model for deformation of an "ideal foliated body". Many of the kinematic details and deformation band geometries observed in stibnite find close analogs with kink bands in these experiments, even though the slip system in minerals is more tightly constrained than in these uniaxially anisotropic bodies. Additional theoretical 
proposals (Bhattacharya, 1977; Anderson, 1974), based on laboratory and field observations, have been made on the direction of kink-band boundary (plane) movement in rocks.

\section{STRUCTURE OF STIBNITE}

Stibnite is an orthorhombic mineral with point group $2 / m 2 / m 2 / m$, which most commonly occurs in a prismatic habit elongated parallel to the $c$ axis. Crystallographic orientation is facilitated by the presence of a perfect cleavage, $\{010\}$. Imperfect cleavages are reported as $\{100\},\{110\},\{001\}$, and $\{101\}$ (Ramdohr, 1969, p. 692; Mugge, 1898, p. 79). The crystal structure of stibnite has been determined by several workers (Hofmann, 1933; Scavnicar, 1960; and Bayliss and Nowacki, 1972). For space group Pnma, the most recent refinement of the lattice constants are reported by Bayliss and Nowacki (1972) as: $a=11.22 \AA, b=11.31 \AA$, and $c=3.83 \AA . *$

The active slip system in stibnite can be envisioned from the crystal structure. Figure 1 shows the stibnite structure in perspective view. This diagram was generated by a computer from atomic position data (See Acknowledgements.). The structure contains two independent $\mathbf{S b}$ sites. The $\mathbf{S b}_{\mathbf{I}}$ atom is coordinated to three $\mathrm{S}$ atoms, forming a $\mathrm{SbS}_{3}$ pyramid. The $\mathrm{Sb}_{\mathrm{II}}$ atom has a more complex square-pyramidal coordination polyhedron. Ribbon-like $\left(\mathrm{Sb}_{4} \mathrm{~S}_{6}\right)_{\mathrm{n}}$ chains cross-link to form a crenulated sheet which is perpendicular to the $b$ axis (Scavnicar, 1960, p. 95). These $(010)$ sheets are held together by two sets of weak van der Waals interactions between $\mathrm{Sb}$ and $\mathrm{S}$ atoms. The atomic separations of the antimony and sulfur atoms across this plane (of $3.33 \AA$ and $3.60 \AA$, Scavnicar, 1960 , p. 94,96$)$ are the largest in the crystal structure. Therefore, the $(010)$ planes are logically the slip planes in stibnite, since they require the least energy to break. The lack of slippage along the (100) and (110) planes is explained by their closer packing and stronger bonding.

The slip direction, [001], is into the plane of the page in Fig. 1. This corresponds to a strongly favored direction of movement along the (010) plane because of the small amount of energy required to break and rejoin adjacent bonds. The stibnites used in our experiments are essentially pure, stochiometric $\mathrm{Sb}_{2} \mathrm{~S}_{3}$. All minor elements were below delection limits $( \pm 0.05 \mathrm{wt} \%$ of amount present) of the energy dispersive system on our scanning electron microscope.

\section{EXPERIMENT AL PROCEDURE}

Real-time observation of deformation banding in stibnite involved the development and combination of compatible techniques and equipment for

\footnotetext{
* The crystallographic nomenclature used by these workers differs from that used in previous structural studies of stibnite. The lattice constants are labeled here according to the more frequent usage.
} 


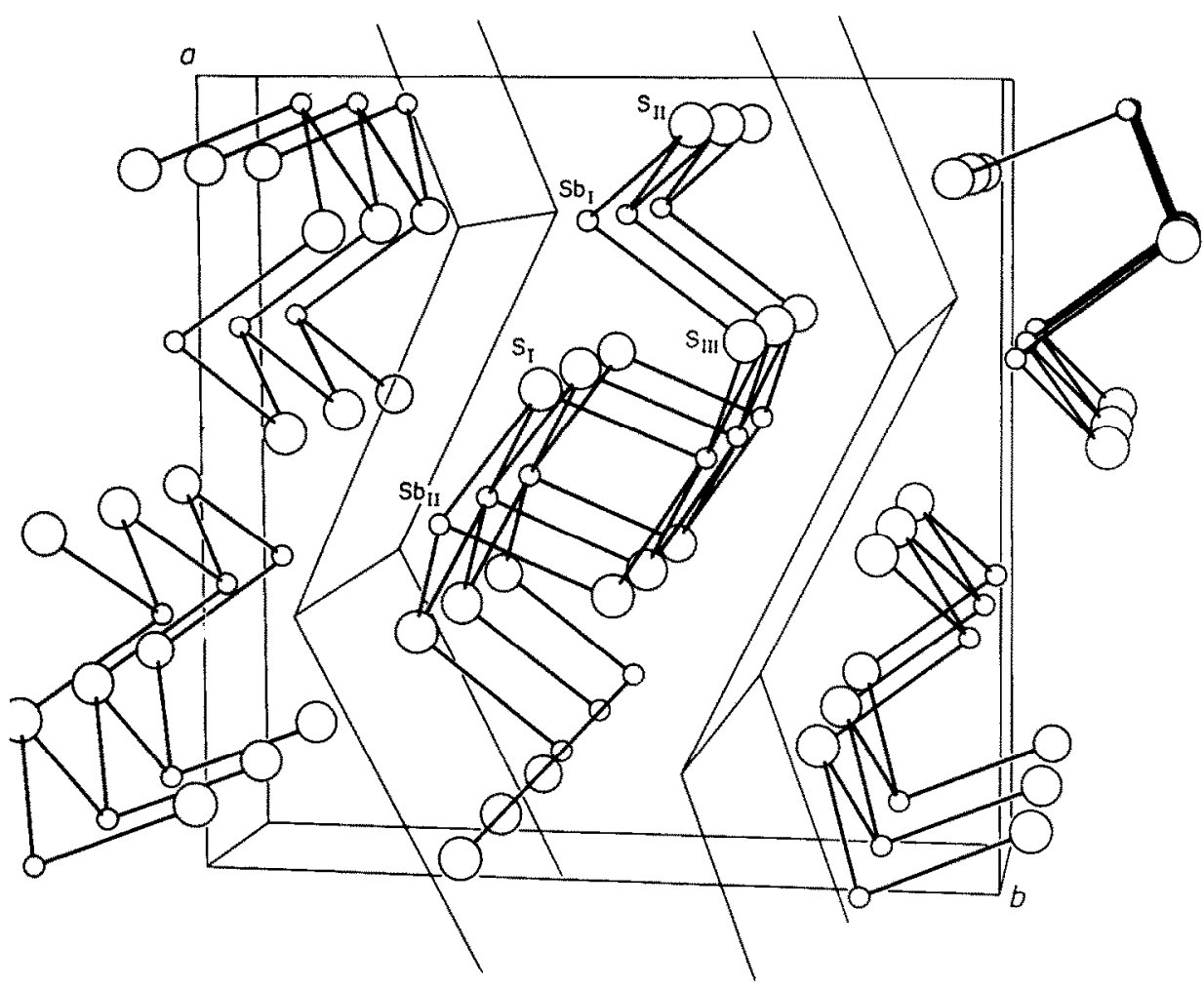

Fig. 1. Crystal structure of stibnite showing two crenulated slip planes (010). Box encloses one unit cell with $b=11.31 \AA$. The strongest bonds are drawn as solid lines.

deformation, sample preparation, and observation. Details are given in the following paragraphs.

The Microscope Stage Strain Device (MSSD) used in these experiments (see Fig. 2A) allows both a flexure and compression deformation mode to be employed. The flexure mode (see Fig. 2B) consists of a three-point beambending configuration, where a hand-activated, screw-type piston contacts the center of a specimen being held against two steel dowels. In this mode, compressive stresses are generated on the concave side and tensile stresses on the convex side of the sample. The compression mode (see Fig. 2C) places the run material in uniaxial compression between a converging and a stationary steel platen.

Because the mineral samples are small and fragile, we found it necessary to mount them in a flexible mounting material which would not only permit us to polish the mineral, but would also permit us to deform the composite sample large amounts in a ductile mode. While several different mounting media (solders, metals, rubbers, and resins) were tested, a heat-softened resin proved most satisfactory for both polishing and deformation. Commercially 


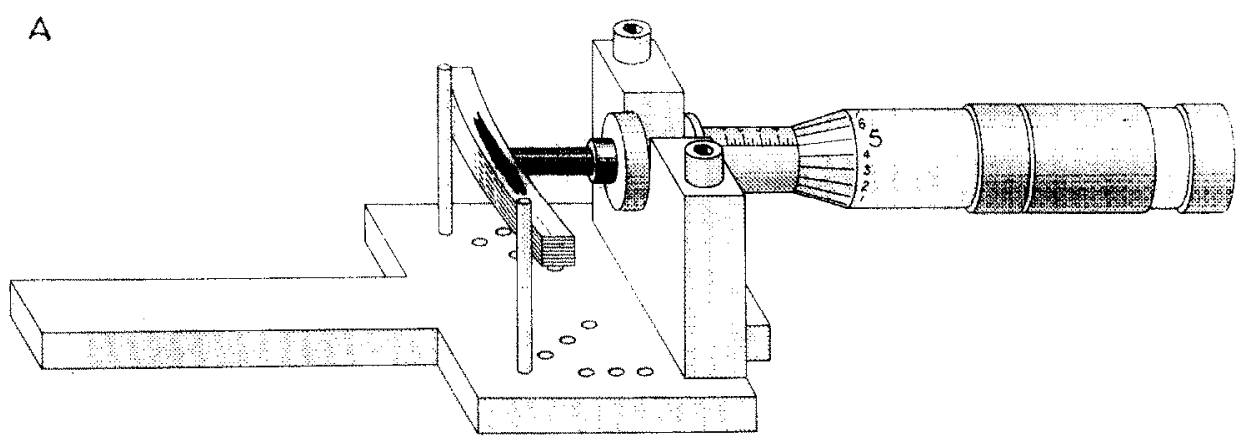

B
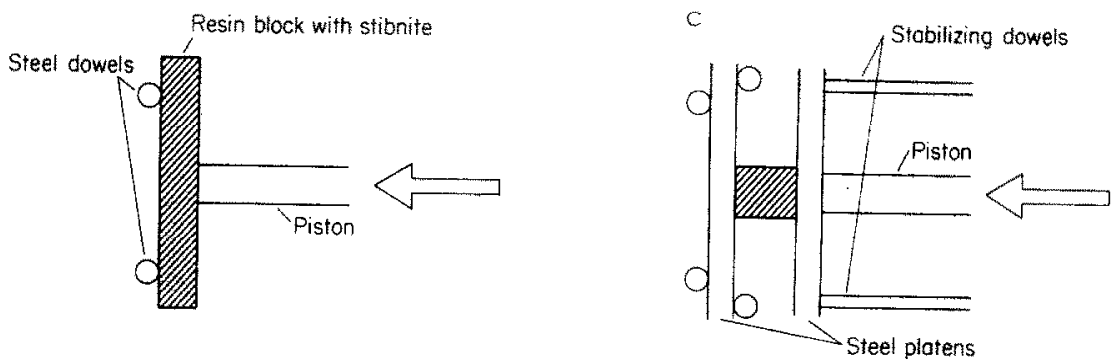

FLEXURE MODE

COMPRESSION MODE

Fig. 2. Microscope Stage Strain Device (MSSD) and deformation modes. A. MSSD in perspective, flexure mode; specimen block under deformation is $3 \mathrm{~cm}$ long. B. Flexure mode in plan view. C. Compression mode in plan view.

available, cold-setting "boat resin"' was prepared with $20 \%$ less hardener than recommended. Stibnite was placed in the resin and polished for use on the reflecting light microscope. Specimens were oriented in the resin mounts using the perfect $\{010\}$ cleavage and consistent elongation of grains parallel to $c$ as guides. Stibnites from Manhattan, Nevada and Mimuriel, Ciudad Real, Spain were used as run materials and they produced the same microstructures. Excellent polished surfaces were obtained by a sequence of silicon carbide $(240,400,600$ mesh on a fast lap, followed by 800 mesh on glass) and aluminum oxide $(15,5,3,0.05$ micron on a slow lap). No deformation bands developed as a result of the polishing procedure.

Elongate blocks of stibnite surrounded with epoxy were cut to dimensions of $25 \times 5 \times 5 \mathrm{~mm}$ for use on the MSSD. The samples were supported on the MSSD by resin blocks and modelling clay, to prevent rotation out of optical focus. Run material was checked before deformation for the location and kind of pre-existing microstructures to prevent confusion with experimentally produced features. The prepared sample was heat softened for five minutes at $100^{\circ} \mathrm{C}$ (if required by the experiment), placed on the MSSD, and 
deformed in either the compression or flexure mode. The piston velocity was on the order of $10^{-3} \mathrm{~mm} / \mathrm{sec}$. In the compression tests, specimen shortening was $2 \%$ over the maximum run length of five minutes, yielding a hand-controlled, longitudinal strain rate of about $10^{-4} \mathrm{sec}^{-1}$ for the MSSD.

The MSSD was attached to a reflected-light microscope stage in order for the kinematic details of the deformation to be captured by television photomicroscopy. A portable color-television camera (Hitachi FP-3030A) was mounted in the optical train of the microscope, using the objectives of the microscope to focus the image. The process of deformation was documented on video tape (using a Sony $\mathrm{AV}-3650, \frac{1}{2}$ ", reel-to-reel recorder) and simultaneously observed on a color monitor. The television photomicrographs allowed the details of the kinematic history of stibnite to be unraveled in a unique way.

\section{EXPERIMENTAL RESULTS}

Over fifty experimental deformations of stibnite were performed, using the Microscope Stage Strain Device just described. Of these, twenty were videotaped and document the observations to follow. The experimental conditions of the runs mentioned in this paper are summarized in Table I.

The optical evidence clearly shows that the primary strain features in stibnite are deformation bands and not deformation twins. Boundaries of the features are generally diffuse under plane-polarized light. Under the scanning electron microscope (SEM) (Fig. 3G), the boundaries appear as zones of complex structural damage and opened cleavages. In addition, the deformed grains exhibit undulose extinction and a variable amount of structural rotation. Two types of deformation bands (Fig. 4E and 4F) have boundaries which parallel the $(001)$ mirror plane in the stibnite structure. Since the twinning operation involves an element of symmetry not present in the untwinned structure (Hobbs et al., 1976, p. 102), these bands cannot be twins.

The experiments failed to produce previously reported twin relations by deformation. Rare twin planes of (130), (310), and (120) have been reported in stibnite (Palache et al., 1944, p. 271). Runs were performed with crystals in orientations which should have produced deformation twinning (Runs 25 and 47 of Table I). No features were produced which could be related to either twinning or deformation-band formation. We conclude that the reported twins were either developed during crystal growth or are deformation-band boundaries which have been misidentified.

\section{Slip system identification}

Single crystals of stibnite were deformed in various crystallographic orientations to test previous observations concerning its slip system (Mugge, 1898; Ypma, 1975). Mugge (1898, pp. 77-78) reported that on compression of stibnite "...(010) is the slip plane; and since simultaneously the prism faces 


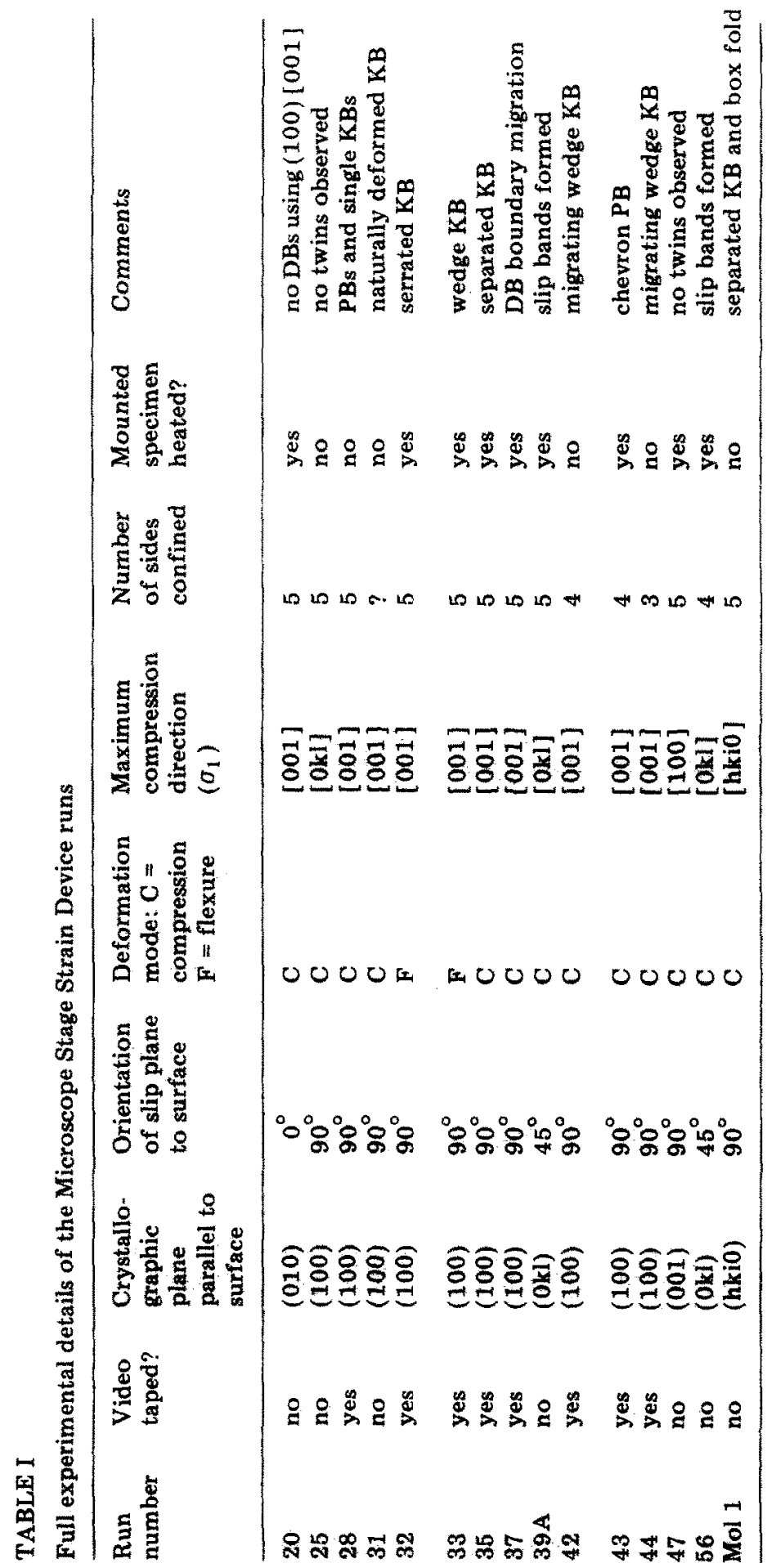




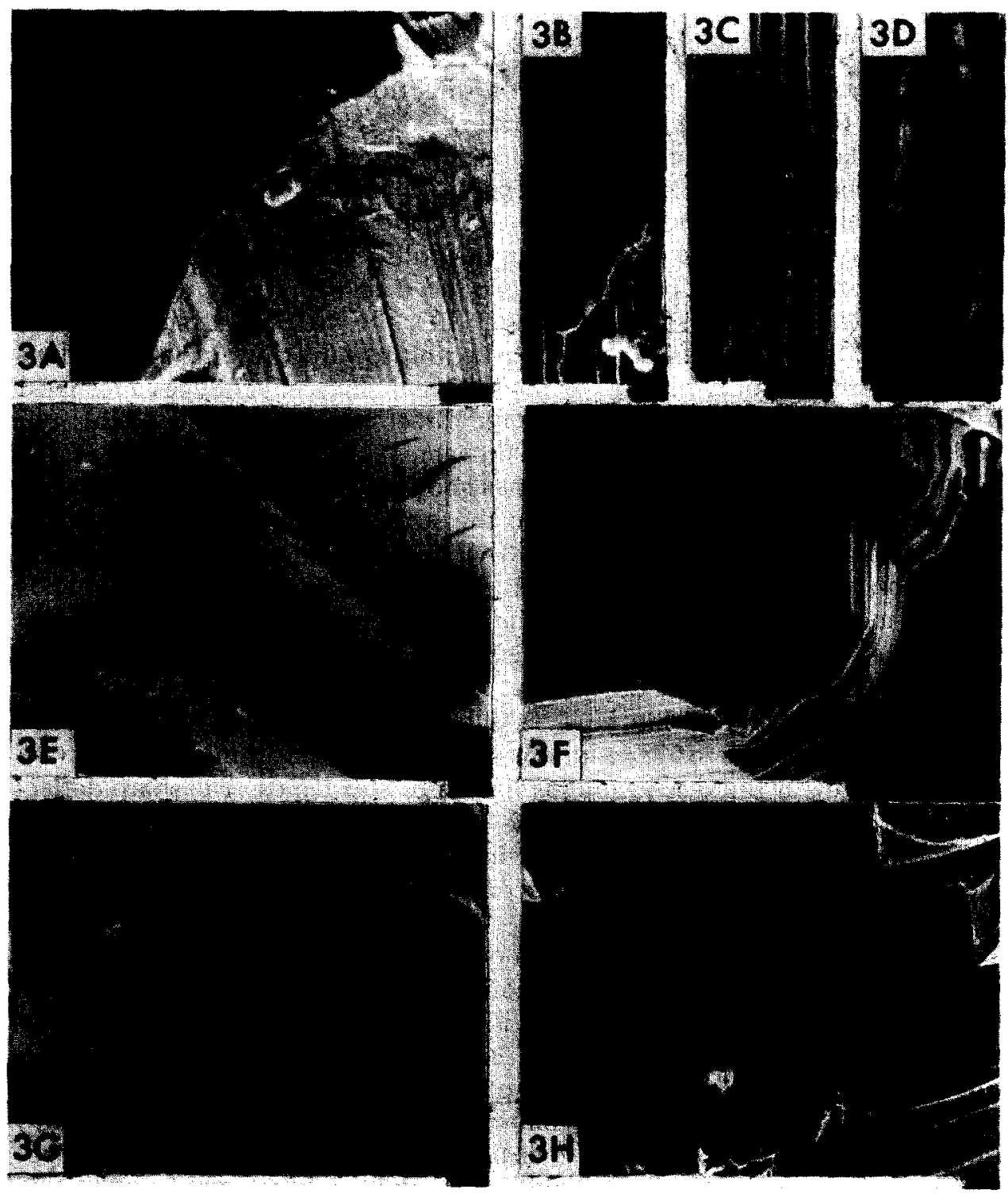

Fig. 3. Scanning electron microscope views of deformed stibnite and molybdenite. See Table I for full experimental details. $A-D$ : bar scale $=5 \mu \mathrm{m}$. E-H: bar scale $=20 \mu \mathrm{m}$. Deformation mode of MSSD: compression; $\sigma_{1}$ : maximum compression direction.

A. Slip bands on polished surface in upper left. Run 39A. $\sigma_{1}:[0 \mathrm{kl}]$.

$B-D$. Increasing magnifications of slip bands. Note discontinuities and faults. $D$ reveals the $\{100\}$ cleavage $(E-W)$ intersecting the $(010)$ slip bands $(N-S)$. Run 56, $\sigma_{1}$ : $E-W$.

E. Wedge kink band plunging to NW. Large open cleavage in SE corner. Run $42 . \sigma_{1}$ : NE-SW.

F. Chevron perpendicular band. Run 28. $\sigma_{1}: \mathrm{NE}-\mathrm{SW}$.

G. Intense deformation and dilation of chevron perpendicular band boundaries (NE$\mathrm{SW})$. Note triangular cleavage pits. Run $42 . \sigma_{1}$ : NW-SE.

H. Separated kink bands in molybdenite. Note space problem at core of box fold. Run Mol 1, $\sigma_{1}: \mathrm{E}-\mathrm{W}$. 
remain free of striations, the translation direction $(t)$ is therefore parallel to $c, t=[001]$ (in agreement with the bending axis being [100])."

The standard test (Buerger, 1930) for determining the planes along which slip can occur consists of three steps. A surface is first polished, then deformed, and later studied for the crystallographic orientation of slip bands. These are step-like offsets along the polished face, produced by translation gliding. Such slip bands were produced in stibnite by uniaxial compression in the MSSD. In Run 39A (Fig. 3A), the $\{010\}$ cleavage plane was placed at $45^{\circ}$ to the polished section, dipping toward the piston. Compression of the resin block, parallel to the polished surface, produces a resolved shear stress in the [001] crystallographic direction. Observation of this run product under the SEM confirms that movement along planes dipping at $45^{\circ}$ did occur. This is evidenced by (1) lines showing relief on the polished surface and (2) the angle of the plane to the surface, seen along the irregular, unpolished side of the specimen (Fig. 3A). From the known crystallographic orientation of the stibnite crystal (Run 39A, Table I), these slip bands indicate movement along $(010)$ in the [001] direction. The resulting slip bands (see also Fig. 7A,B) were visible in ordinary reflected light and enhanced using interference objectives.

In addition to confirming Mügge's slip system, the observed slip bands show complex results of translation gliding. SEM photomicrographs (see Fig. 3B-D) reveal the discontinuous nature of slip bands. The sharp deflections and abrupt terminations of these features are indicative of barriers to translation in the crystal structure. At increased magnification (Fig. 3D), the trace of the $\{100\}$ cleavage planes becomes clearly evident, perpendicular to the $(010)$ trace.

No translation along any slip system other than (010) [001] was produced during these experiments. An indication of translation gliding is the formation of deformation bands, because it is the deformation mechanism responsible for their production (Hess and Barrett, 1949, p. 599). Deformation bands consistent with any other slip plane or direction were not observed. For example, Run 20 (Table I) failed to produce bands using the (100) [001] system, under what were logically the best conditions for their production. Since cleavages often develop parallel to slip planes, imperfect cleavages (such as (100)) were observed carefully during deformation. The only microstructure involving these other planes was microfracturing due to cataclasis.

\section{Deformation features.}

The major deformation features observed in experimentally deformed stibnite were: breccia fragments, bent cleavages, opened_cleavages, slip bands, microfolds, and deformation bands. The main deformation mechanisms active in stibnite are therefore concluded to be translation gliding (slip) and cataclasis. Of the features mentioned above, deformation bands 
were the most important microstructure developed. In the following sections, the geometric terminology, classification scheme, and statistical data for the deformation bands observed in stibnite will be treated.

The geometric terms, such as kink band boundary, $\phi$ and $\phi_{\mathrm{k}}$ angles, and width, used in the following discussion are defined in Weiss (1969). The classification scheme presented below is an extension of that proposed by Weiss (1969).

Most workers have lumped all deformation bands in minerals under the heading "kink band" (Starkey, 1968; Etheridge et al., 1973; and Clark and Kelly, 1976), considering variations of the boundary orientation over the range $45^{\circ}-105^{\circ}$ to be statistical scatter, still resulting from kink-band mechanics. Ramsay's (1967) theoretical and our experimental work suggests that a distinction should be made. While a variety of deformation band types were observed in experimentally deformed stibnite, they fall into two basic categories. These categories are defined by the angle $\phi$ between the boundary and the undeformed slip plane. The first category consists of true kink bands with $\phi$ angles averaging around $70^{\circ}$. Kink bands have been the most common microstructure observed in stibnite. At the same time, significant deformation bands formed at high angles to the slip plane that are more closely related to the mechanics of chevron folding than of kinking. These deformation bands have $\phi$ equal to approximately $90^{\circ}$ and are termed perpendicular bands in our classification scheme. Ramsay (1967, pp. 436-456) has derived the stress-strain mechanics of chevron folding and kinking in foliated materials, showing that they are indicative of different stress regimes. This justifies a classification scheme, such as follows, which does not put all deformation bands into the "kink" category. Hereafter, deformation band will be abbreviated "DB"; kink band, "KB"; and perpendicular band, "PB". In the discussion to follow, when "DB" is used without modifiers it is a general term including both KBs and PBs.

The variety of DBs within the two broad categories just treated requires a classification system to allow a coherent discussion of their kinematics. The types of KBs observed are: single, separated, wedge, and serrated. Single and chevron are the two kinds of PBs. Single KBs (Figs. 4A and 5A) are single DBs with boundaries oriented at about $65^{\circ}$ to the undeformed slip plane. A band of this type may be either "right" (as in Fig. 5A) or "left" handed, depending on how the kinked portion rotates. Separated KBs (Figs. $4 \mathrm{~B}$ and $\mathrm{5B}$ ) are paired sets of single $\mathrm{KBs}$ with boundaries which converge, yet do not meet. Separated KBs were found to be asymmetrical, with one element of the conjugate generally longer than the other. Having a higher $\phi$ of $75^{\circ}$, wedge $K B s$ meet along a boundary which separates two deformed regions of the crystal. A wedge KB is seen in Figs. 4C and 5C. Serrated KBs include segments geometrically equivalent to the last type. They are a fascinating microstructure consisting of multiple-wedge $\mathrm{KBs}$ joined along a straight to en-échelon zone in a zig-zag manner (Figs. 4D and 5D). Both single and cheuron PBs have boundaries that are approximately normal to 
A. Single

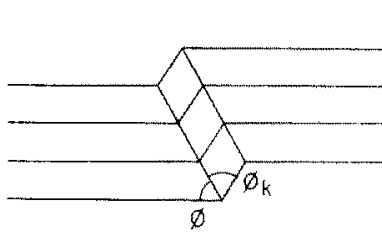

B. Separated

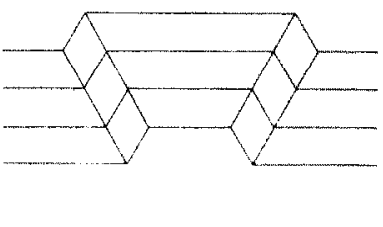

C. Wedge

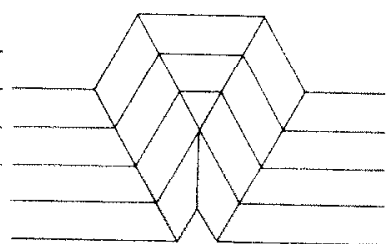

D. Serrated

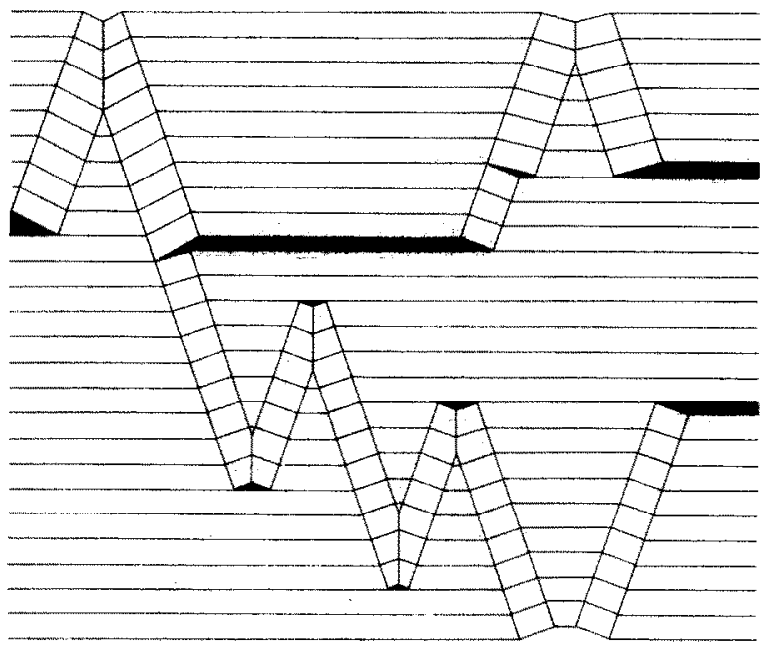

PERPENDICULAR BANDS

E. Single

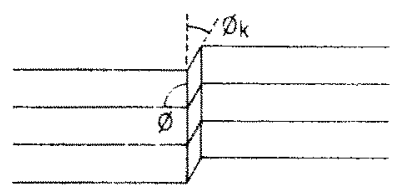

F. Chevron

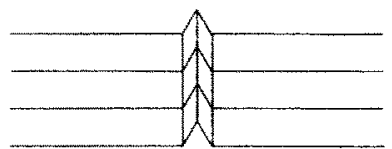

Fig. 4. Schematic diagrams of the types of deformation bands observed in experimentally deformed stibnite. Maximum compression direction: E-W, and parallel to [001]. (010) is normal to the plane of the page.

the slip plane. Single PBs are solitary bands (Figs. 4E and $5 \mathrm{E}$ ), whereas chevron PBs consists of two adjacent single PBs with opposing deflections of the slip plane (Figs. $4 \mathrm{~F}$ and $5 \mathrm{~F}$ ). Another way to view this latter type of $\mathrm{PB}$ is as a chevron fold in the crystal structure. The proposed classification system 
may be summarized as:

Types of deformation bands

I. Kink bands
A. Single
B. Separated
C. Wedge
D. Serrated

II. Perpendicular bands
A. Single
B. Chevron

The frequency of occurrence of DB types, and the angles $\phi$ and $\phi_{k}$, were measured for a sample of sixty deformation bands, chosen at random from twelve different runs. The determinations were made through the microscope and from the video tape monitor. Rather than using extinction positions as references for the angular measurements, $\phi$ and $\phi_{\mathrm{k}}$ were determined by reading the angle between open cleavages and DB boundaries. The angles were measured on cross-sections perpendicular to the structure, and are thus true rather than apparent angles. The statistical data on the different DB types are:

\begin{tabular}{lllc}
\hline & $\begin{array}{l}\text { Frequency } \\
\text { of occur. } \\
\text { rence }\end{array}$ & $\phi$ & \multicolumn{2}{c}{$\mathrm{n}=60$} \\
\cline { 3 - 4 } & $39 \%$ & $64^{\circ} \pm 9^{\circ}$ & $68^{\circ} \pm 9^{\circ}$ \\
\hline Single KBs & $33 \%$ & $74^{\circ} \pm 8^{\circ}$ & $63^{\circ} \pm 9^{\circ}$ \\
Wedge KBs & $17 \%$ & $87^{\circ} \pm 3^{\circ}$ & $64^{\circ} \pm 7^{\circ}$ \\
Chevron PBs & $5 \%$ & - & - \\
Serrated KBs & $3 \%$ & - & - \\
Separated KBs & $3 \%$ & - & - \\
Single PBs & & &
\end{tabular}

The high standard deviations of some angles are not a function of measurement precision alone (which was estimated at $\pm 3^{\circ}$ ). Rather, they are indicative of true variability of deformation band geometry. Were these features twins, a much lower deviation about the mean would be expected. Note that the $\phi_{\mathrm{k}}$ value is approximately the theoretical value of $60^{\circ}$. As the geometry becomes more complicated in wedge $\mathrm{KBs}$, the angle $\phi$ increases to $74^{\circ}$. Chevron PBs show a tighter distribution of $\phi$ around $87^{\circ}$. These differences are due to contrasting mechanics of deformation banding between those types with means around $70^{\circ}$ and those averaging around $90^{\circ}$ (See Discussion).

The width of DBs is not a function of the particular type. As can be seen on various photographs (Figs. 3 and 5), the width of all the DBs, except the serrated, are in the range 50-200 $\mu \mathrm{m}$. The width of any one conjugate segment of the serrated $\mathrm{KB}$ is generally less than $25 \mu \mathrm{m}$. 

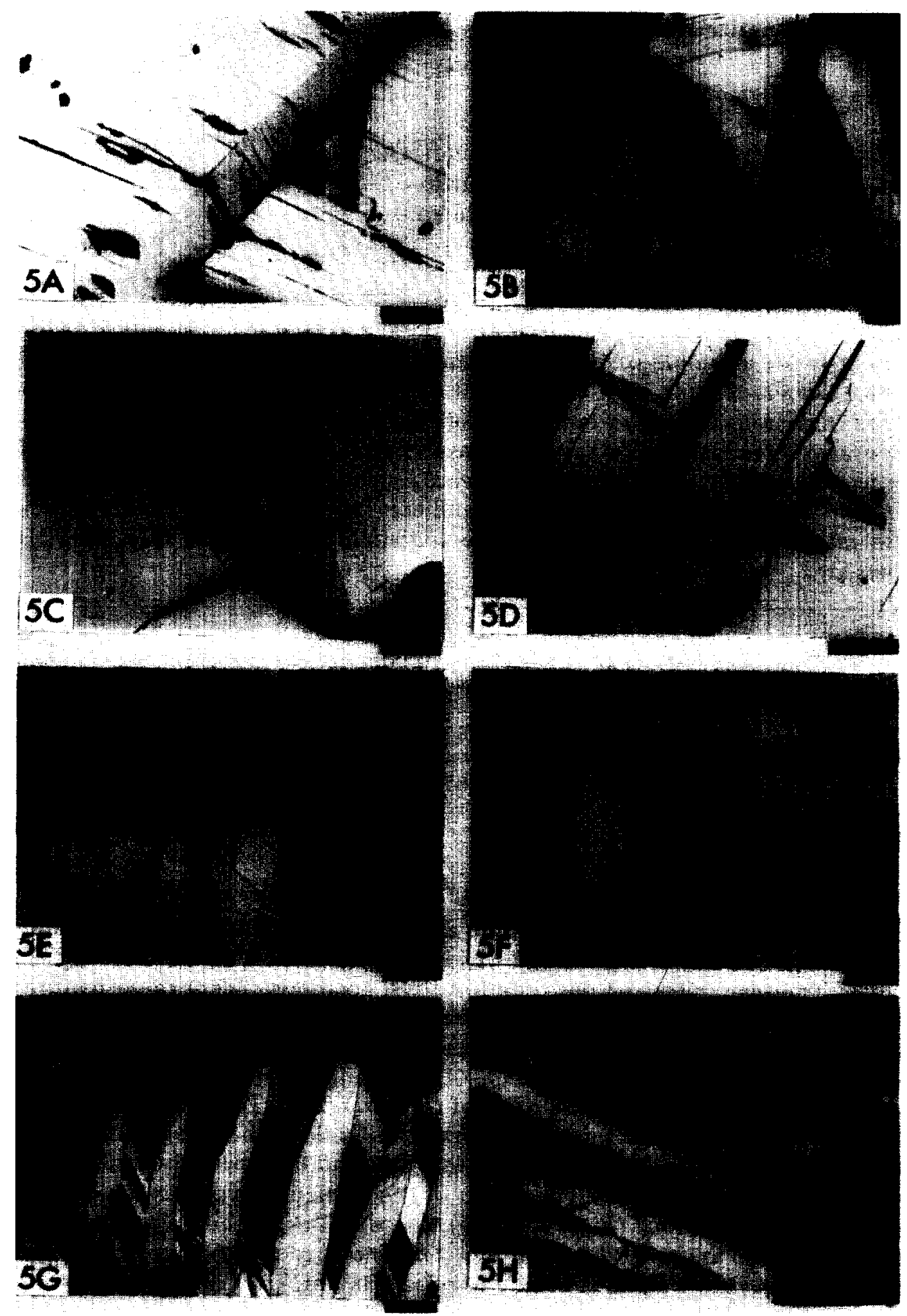


\section{Kinematics of deformation bands}

Since the detailed stress distribution within the polyester resin mount was not determined, the dynamics of DB formation in stibnite cannot be quantitatively addressed. However, the kinematics of the process can be treated because the growth and modifications of DBs was directly observed during deformation. The kinematic history (for discussion of this term as applied to rocks, see Means, 1977, p. 169) of stibnite DBs may be divided into four stages - initiation, migration, termination, and modification. The general descriptions of each of these stages are given below, followed by a discussion of four deformation sequences documented through single-frame photographs taken from the video-taped experimental runs.

The first stages of deformation banding, initiation and migration, involve two different senses of boundary movement. Weiss $(1969$, p. 307) calls initiation, "longitudinal propagation" and migration, "lateral propagation". Initiation refers to the localization of strain into a discrete band. This requires the lengthening (Fig. 6A,B) of the deformation band from some point of nucleation. Of course the DB cannot be a euclidean point at nucleation, but must have some length and width. Although several workers have speculated concerning KB nucleation (Baer and Norris, 1969), we cannot address the issue in any detail because our experimental technique precluded the documentation of the rapidly occurring DB nucleation. Once nucleation is complete, the microstructure's boundaries may begin to migrate outward. In contrast to initiation, migration produces a widening of the band (Fig. $6 \mathrm{C})$.

\section{Initiation}

Three deformation features in various combinations have been observed to precede DB initiation in stibnite: gentle folding (Fig. 7F), cleavage dilation

Fig. 5. Reflected light photomicrographs of deformation bands in experimentally produced $(B-F)$ and naturally formed $(A, G-H)$ stibnites. $A-F:(010)$ perpendicular to the plane of the page in cross-sectional view. Bar scale $=100 \mu \mathrm{m}$. See Table I for full experimental details. $\sigma_{1}$ : maximum compression direction.

A. Single kink band. Run 31. $\sigma_{1}:$ NW-SE (inferred).

B. Separated kink band. Arrows point to conjugate parts of band. All other major bands in field of view are lefthanded, simple kink bands. Run 35. Compression mode, $\sigma_{1}: \mathrm{E}-\mathrm{W}$.

C. Wedge kink band. Run 44. Compression mode, $\sigma_{1}$ : NE-SW.

D. Serrated kink bands. Run 32. Flexure mode, $\sigma_{1}: \mathrm{NE}-\mathrm{SW}$.

E. Single perpendicular band (labeled $p b$ ). Run 28 . Compression mode, $\sigma_{1}: \mathrm{E}-\mathrm{W}$.

F. Chevron perpendicular bands. Run 43 . Compression mode, $\sigma_{1}: \mathrm{E}-\mathrm{W}$.

G. Two generations of deformation bands from La Tarnia, Spain. Chevron perpendicular bands $(\mathrm{N}-\mathrm{S})$ imply an initial $\sigma_{1}$ of $\mathrm{E}-\mathrm{W}$, then the wedge kink bands (NW-SE) imply a later $\sigma_{1}$ of $\mathrm{NE}-\mathrm{SW}$.

H. Scalloped deformation band texture from the Stibnite Hill, Montana locality. Texture is concluded to be modified by annealing. Specimen 77 (random orientation), $\sigma_{1}$ : $\mathrm{NE}-\mathrm{SW}$ (inferred). 


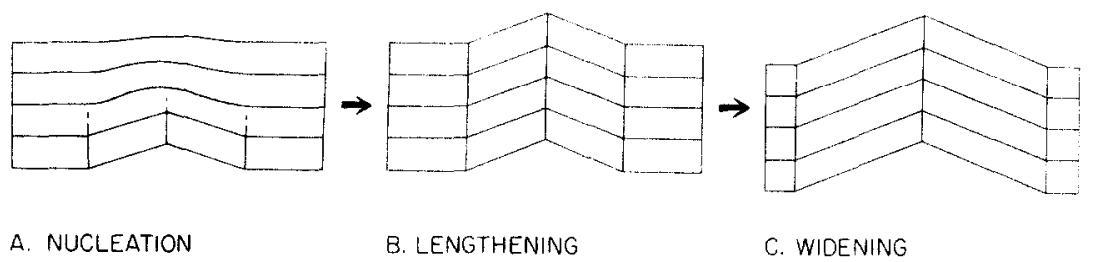

Fig. 6. First two kinematic stages of deformation banding in stibnite.

A-B. Initiation stage. Deformation band nucleates as a ductile bulge in the mineral, then lengthens.

C. Migration stage. Widening of the band dominates over lengthening.

(Figs. 3G and 5B), and slip band formation. Slight $c$ axis misalignment allows slip bands to be seen in reflected light (Fig. 7A,B). The appearance of slip bands, indicating the occurrence of translation gliding, is a logical antecedent to deformation banding.

The variable which appears to control the position of $\mathrm{DB}$ initiation is the local stress field within the grain. Deformation consistently began on the end (or side, for the flexure mode) of the specimen nearest the piston and propagated into undeformed regions. However, the different types of DBs nucleated under characteristically different mechanical conditions. Single KBs nucleated in areas of low confinement near the specimen-mount interface or in areas where cataclasis, along with the opening of cleavages, produced significant open space. The large amount of external rotation involved in simple kinking is mechanically favored by such open space (Fig. 5A). The various types of conjugate $K B s$, i.e. separated, wedge, and serrated, often form near open cleavages or fractures, with the sense of longitudinal propagation being away from the surface imperfection and toward undeformed matrix (Fig. 7A,B). The available open space in which conjugate $\mathrm{KBs}$ form is generally less, however, than that for single KBs. In contrast, single and chevron $\mathrm{PBs}$ seldom nucleate adjacent to open cleavages or fractures. Instead, they involve an entire undeformed segment of the grain in zones of greater confinement. Serrated KBs occur more frequently in flexed samples than those compressed uniaxially. They are commonly associated with fracture

Fig. 7. Photographs from screen of video-tape monitor, displaying deformation band kinematics in stibnite. See text for details of the kinematic sequence. Base scale $=100 \mu \mathrm{m}$.

A-B. Initiation of a wedge kink band. Note slip bands visible on deformed segments of wedge kink in A. Run 42. Compression mode, $\sigma_{1}: \mathrm{E}-\mathrm{W}$.

$C-D$. Initiation (C) and termination (D) of a serrated kink band. Run 32. Flexure mode, $\sigma_{1}: \mathbf{N}-\mathbf{S}$.

$\mathrm{E}-\mathrm{H}$. Initiation (E-F), migration-termination $(\mathrm{G})$, and modification $(\mathrm{H})$ of single perpendicular bands and single kink bands. Run 28. Compression mode, $\sigma_{1}: \mathrm{E}-\mathrm{W}$.

$\mathrm{I}-\mathrm{L}$. Initiation (I-J), migration (K), and termination (L) of a wedge kink band. Run 44. Compression mode, $\sigma_{1}: \mathrm{E}-\mathrm{W}$. 


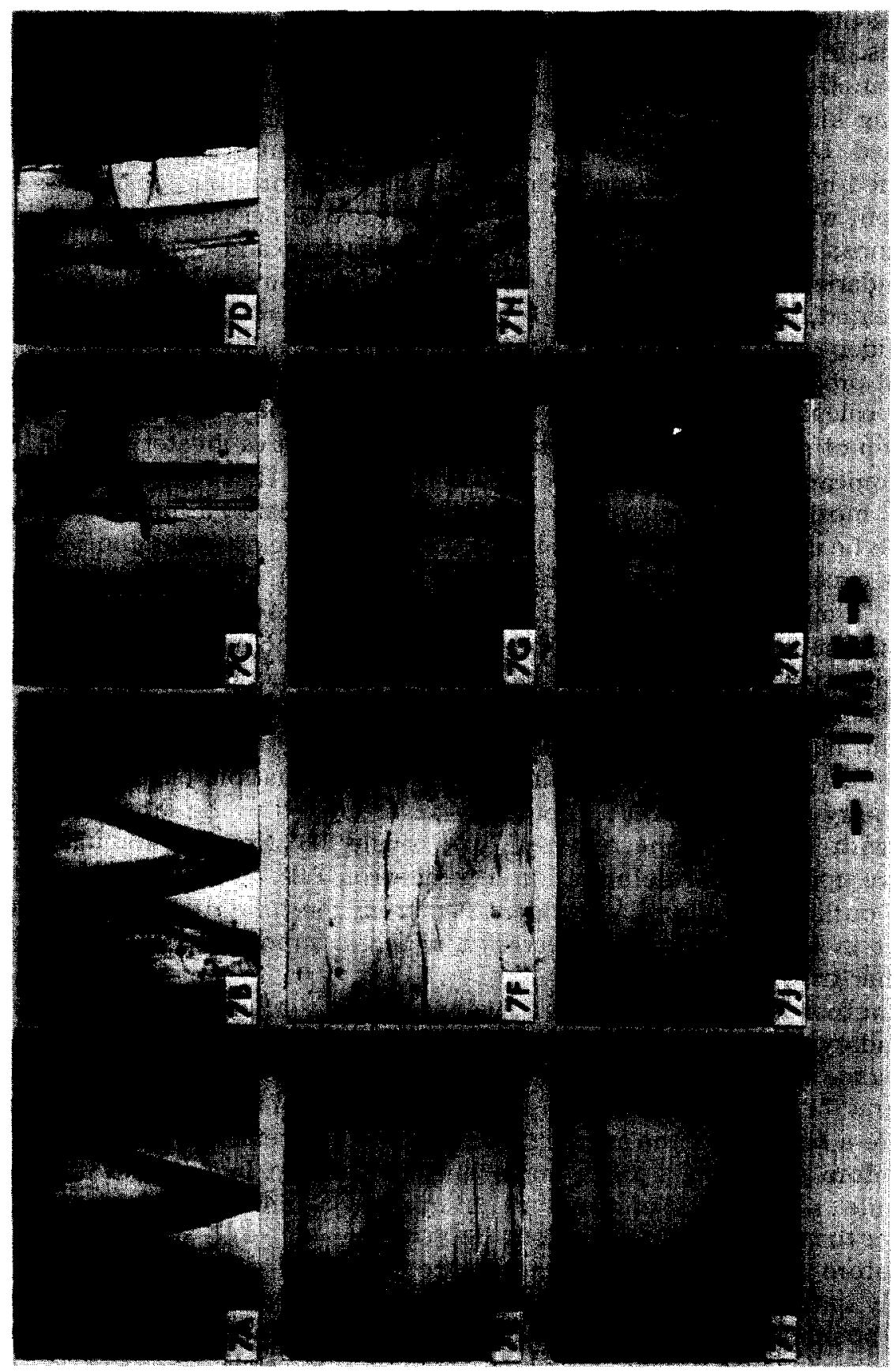


zones, indicating localization of high stresses along a narrow shear zone and/or a free surface into which the band could grow. Like PBs, they are not closely tied to surface imperfections, open cleavages, or open space. An additional place of localization for $\mathrm{KBs}$, in particular, is in rotated breccia fragments. In a zone of cataclasis, the chips will often rotate and impinge upon one another in such a way as to activate the (010) [001] slip system, producing kinks. New DBs frequently initiate immediately adjacent to earlier formed DBs (Fig. 8I-L). Logically, this is because slip is mechanically favored near an area of prior deformation. Therefore, the local stress distribution, which is determined by: (1) experimental design; (2) surface imperfections; (3) confinement; (4) breccia fragments; and (5) pre-existing DB boundaries, appears to control not only the location but also the type of DB nucleated.

Video-taped runs of wedge-KB initiation revealed that the rate of longitudinal propagation is also controlled by the amount of confinement. The rate was calculated by calibrating the resolution of the video-tape recorder in slow-motion mode. Movement occurring at velocities greater than $0.1 \mathrm{~mm} /$ sec appeared instantaneously, even in slow motion. By timing the initation in slow motion, then measuring the length of the band, a minimum velocity could be determined. In a run during which the specimen was confined on all sides except the polished surface (Run 33, Table I), an initiation rate greater than $1 \mathrm{~mm} / \mathrm{sec}$ was measured. In contrast, Run 44 had three unconfined sides, resulting in a slower propagation (less than $0.5 \mathrm{~mm} / \mathrm{sec}$ ). In all cases of deformation banding in stibnite, regardless of type, deformation mode, or confinement, the lengthening of the band was faster than its widening.

The basic geometry of a DB is predestined at the time of initiation. In these experiments with stibnite, once a deformation band attained the geometry of a single $\mathrm{KB}$, its boundary never rotated to the subperpendicularity with the slip plane required for a single PB. Nor did conjugate types evolve upon further deformation into chevron PBs. In fact, all the types of DBs outlined in Fig. 4 were identified from the time of initiation at some point in this study - an observation which is important in considering the further growth of DBs.

Another feature sometimes developed at initiation is offsets in the DB boundary. These offsets could be easily mistaken in naturally deformed ores for some sort of later modification of a preexisting continuous boundary. Figures $7 \mathrm{~F}$ and $7 \mathrm{G}$ show such an offset forming in the right-most single $\mathrm{PB}$, where a segment of the crystal structure does not bend and dilate as the rest, therefore producing a jog in the incipient boundary. In a naturally deformed stibnite, such an offset could be interpreted as an evidence of later shear, rather than a feature of initiation.

Before any of the migration mentioned below occurs, a change in the newly initiated boundary takes place, producing a pronounced optical effect. The boundaries of the bands are consistently vague upon initial propagation, then sharpen into distinct lines as deformation proceeds. 


\section{Migration}

There have been two contrasting viewpoints concerning the growth of kink bands in rocks and modelling materials (For additional discussion see Anderson, 1974, p. 368.). Bhattacharya (1977) concludes that the width of the KB does not grow. The KB boundaries simply move toward one another as deformation proceeds. On the other hand, Rondeel (1969) maintains that the $\mathrm{KB}$ does indeed grow, with the $\mathrm{KB}$ boundaries migrating outward away from the zone of initiation. In the laboratory studies of Weiss (1969), boundaries have been seen to grow outward; yet in the investigations of Donath $(1969$, p. 255) experimentally produced KB boundaries were inferred to compress inward. This study of stibnite, in agreement with that of Anderson (1974, p. 369) using slate, suggests that both modes occur, but at different stages in the kinematic history.

The term "migration" needs further clarification. Boundaries migrate, in our usage, because new portions of the crystal are added to, or subtracted from, the deformed band. The addition of deformed segments results in the widening of the initial band. Although not recorded in stibnite, DB boundaries in some metals migrate due to "unkinking". Two boundaries may, in contrast, move inward due to pivoting about the hinge of the flexural slip fold. This produces a band width reduction but not a true migration, since deformed material is not being restored to its pristine state. The latter case will be treated below under "modification".

With shades of the anthropomorphism of William Morris Davis, there seem to be certain "youth, maturity, and old age" aspects to the growth of DBs. Evidence from Runs 37 and 42 indicate that in the early stages of deformation, boundaries do migrate outward from the zone of initiation. However, there is equally good documentation (Runs 28, 32, and 42) that once the slip plane has rotated to a certain point, the boundaries become fixed or move toward one another as the deformed segment simply pivots without growth. Observation of the product of Run 37, which showed outward migration, revealed that the two rotated segments of the wedge $\mathrm{KB}$ were at a high angle $\left(\phi+\phi_{\mathrm{k}}=150^{\circ}\right)$ to one another. A similar analysis of the video tape footage of Run 28 (Fig. 7G) demonstrated an immediate rotation to $\phi=\phi_{\mathrm{k}}=60^{\circ}$ for the single $\mathrm{KB}$ which had no outward boundary migration. Therefore, the angle of initial rotation of the deformed segment of the DBs appears to control the possibility of outward boundary migration in stibnite under these experimental conditions.

Migration rate and changing orientation of boundaries were carefully noted during the experiments. The velocity of migration is slower than that for initial nucleation. An approximate velocity for the boundary migration seen in Run 37 was $0.2 \mathrm{~mm} / \mathrm{sec}$, at least an order of magnitude less than the fastest longitudinal propagation recorded. As migration progressed, the angle $\phi$ for any type of DB was not observed to change. This constancy of boundary orientation with respect to the undeformed slip planes implies that 
boundaries develop parallel to pre-existing ones as the band widens. DB boundaries may have jogs which segment the boundary. Each segment was observed to migrate at a rate independent of the other. When one segment would overtake another, they would sometimes coalesce (Fig. 7A,B) and continue migration. Thus, for part of their kinematic development, individual DBs may grow as two or more separate structural units. In the context of migration, it is significant that the boundaries of $\mathrm{DBs}$ present before the experiment were never seen to migrate.

\section{Termination}

Initiation of DBs ends by any one of the following conditions: (1) the meeting of the grain/mount interface; (2) intersection with major open cleavages; (3) encountering of grain boundaries; (4) wedging; or (5) opening of triangular cleavage pits. Logically, the propagation of DBs ceases when encountering the mount itself. Usually only one end of a DB makes it to this point because of other structural discontinuities which arrest the motion. Intersecting a major open cleavage (as at the top of Fig. 7I-L) stops initiation. Propagation will continue across only if the cleavage is sufficiently tight (as in the middle of Fig. $7 \mathrm{E}-\mathrm{H}$ ). Because of the crystal structure misfit across grain boundaries, initiation is terminated here also. Grain boundaries are not quite the same as open cleavages. As with cleavages, a DB may terminate at the edge of a grain or migrate across, depending on the degree of structural discontinuity, with the latter case probably being the most rare. What geometrically otherwise is forming as a chevron DB may terminate in a wedge shape, due to a change in stress magnitudes across the grain (Compare with Fig. 5F,G.). Longitudinal propagation may be stopped by the opening of triangular cleavage pits, such as shown in Figs. 3G, 7A, and 7K. In summary, the two main controlling parameters for the termination of initiation (the lengthening phase) are the ending of crystal structure continuity or changes in the local stress regime within the specimen.

\section{Modification}

Throughout the preceding stages, DB boundaries have remained straight (with the exception of jogs formed at initiation mentioned earlier) whether they converge or are parallel (Fig. $\mathbf{5 C}$ and $5 \mathrm{~F}$ ). After their initiation, migration, and termination, DBs have been found to be modified by shearing and bending (Fig. $7 \mathrm{H}$ ). A particular modification noted in other foliated materials, termed "second generation KBs" by Etheridge et al. (1973, p. 27), have not been observed in our stibnite experiments. They reported DBs forming entirely within the previously rotated segment of the band. Similar features were, however, noted in naturally deformed stibnites (Fig. 5G). The discrepancy between the two responses might be due to the low confining pressure in our experiments. 
The fractures preferentially followed the $\{010\}$ cleavage planes in their rotated position. Fracturing also utilized the DB boundary as a zone of weakness by which to ramp from one part of the structure to another.

\section{Examples of complete deformation sequences}

In order to tie together many of our experimental observations, four deformation sequences will be summarized. See Table I and Figure 7 for the details of the experimental conditions and crystallographic orientation of the stibnite.

Partial kinematics of wedge KBs. In Fig. $7 \mathrm{~A}$, two clear wedge KBs have reached the stage of termination. Note the presence of visible slip bands in the larger and a triangular cleavage pit terminating the smaller KB. Moments later, in Fig. 7B, a third wedge KB initiates and migrates. Significantly, the termination of migration of its left $\mathrm{KB}$ boundary is apparently caused by intersection with the $\mathrm{KB}$ boundary of the adjacent $\mathrm{KB}$.

Partial kinematics of serrated KBs. Figure 7C illustrates the initiation of portions of the serrated KB in an en-échelon pattern, which is associated with open cleavages. Further initiation resulting in the completion of "missing links" in the chain of KBs is exhibited in Fig. 7D. Boundary migration is slight. Note that the initiation of segments is not sequential. Weiss (1969) experimentally produced a banding with similar "zig-zag" geometry, but with the exception that each "zig" followed the previous "zag".

Complete kinematics of single PBs. Figure $7 \mathrm{E}$ shows the undeformed stibnite crystal. In Fig. $7 \mathrm{~F}$, the gentle folding of slip planes and dilation of cleavages may be observed. Figure $7 \mathrm{G}$ documents the longitudinal propagation (initiation) of single PBs across tight cleavage openings, while being terminated by large cleavages. Note the formation of jogs in the DB boundary. Longitudinal propagation of single $\mathrm{KBs}$, meeting but not intersecting the single PBs may also be seen. Note between Fig. $7 \mathrm{~F}$ and Fig. $7 \mathrm{G}$ the closing of the open cleavages adjacent to the right hand boundary of each single $\mathrm{PB}$, as the single $\mathrm{KB}$ forms. Most of the $\mathrm{KBs}$ and $\mathrm{PBs}$ are terminated in this frame. In Fig. $7 \mathrm{H}$, band width reduction of the single PB occurs. Initiation of new DBs in previously undeformed areas takes place. Additional DBs most often initiate in undeformed areas immediately adjacent to previously existing DBs. Modification of boundaries by shearing and bending may be noted in this frame.

Complete kinematics of wedge KBs. An undeformed area of this experimental run is shown in Fig. 7I. The opening of cleavages as precursors to initiation is documented by Fig. $7 \mathrm{~J}$. Note the formation of incipient KB boundaries near the bottom of the frame. The wedge KB geometry is set from this early initiation stage. At this point, $\phi=70^{\circ}$ and $\phi_{\mathrm{k}}=80^{\circ}$, longitudinal propagation occurs rapidly. Expressed as a vector, the sense of this lengthening is toward the top of the frame. In Fig. $7 \mathrm{~K}, \phi=70^{\circ}$, migration stage is reached. Some modification has begun with the compression of the 
rotated wedge KB segments, as evidenced by the reduction in the $\phi_{\mathrm{k}}$ angle. The termination of initiation in triangular cleavage pits further dilates the structure. Another KB initiates to the left of the frame. During Fig. 7L, $\phi=70^{\circ}$ and $\phi_{\mathrm{k}}$ changes to $65^{\circ}$, as further modification proceeds. The firstformed KB terminates its migration against an adjacent KB boundary. Note that: (1) the triangular cleavage pit at the "nose" of the wedge KB propagates along with the band as it lengthens; (2) dilation occurs at KB boundaries as deformation proceeds; and ( 3 ) the wedge- $\mathrm{KB}$ boundary remained at a constant $\left(\phi=70^{\circ}\right)$ angle during its kinematic history, whereas the $\phi_{\mathrm{k}}$ angle compressed from $80^{\circ}$ to $65^{\circ}$.

\section{DISCUSSION}

\section{Ramsay's model of cheuron vs. kink folding}

Ramsay (1967, pp. 440-452) has calculated the shear strain across discrete slip planes for both chevron and kink folds. Although applied to folds in anisotropic rocks, his mathematical treatment is also appropriate for deformation banding in stibnite. His conclusions are as follows:

(a) A chevron fold cannot nucleate, because of low shear stresses, unless the slip plane is slightly curved or the stresses lead to the production of a wave instability and the formation of buckles (p. 443).

(b) After the initial stress-strain threshold is overcome, it becomes mechanically easier for a width reduction (compression of the structure) to occur in chevron folds (p. 445).

(c) Increasing shear-strain increments on the slip plane surfaces of chevron folds lead to a "locking up" of the fold structure (p. 444).

(d) A similar sequence is derived for kink folds (p. 447-450), with the major contrast being that it requires less work to nucleate $\mathrm{KBs}$, than it does chevron folds. Therefore, he concludes, "It seems likely that primary chevron folds only form where the hinges are initially fixed by a buckling process which produced sinusoidal fold waves" (p. 450).

Ramsay's treatment provides a mechanical model for several aspects of DB kinematics. Recall in Fig. $7 \mathrm{~F}$ how gentle folding preceded the formation of the single $\mathrm{PB}$, but the area in which single $\mathrm{KBs}$ propagate is not buckled. Such precursory folding in the early initiation stage appears to be mechanically required for $\mathrm{PBs}$. Otherwise, some type of $\mathrm{KB}$, requiring less resolved shear stress to initiate, will form first. Experimental support for this conclusion has been found in the fact that when more than one type of DB forms during a run (e.g., Fig. $7 \mathrm{E}-\mathrm{H}$ ), the $\mathrm{PB}$ types are usually first, when the elastic stress build-up in the resin mount is at its highest. The rapidity of initiation is explained by the strain energy required to overcome the inherent stability of the undeformed structure. When this instability is reached, longitudinal propagation proceeds rapidly as the accumulated potential energy is dissipated. The model explains the band width reduction 
and the locking up of the DBs noted in stibnite. Ramsay's development falls short in some kinematic areas where an explanation may be found in dislocation theory.

\section{DBs and dislocation theory}

As applied to DB boundaries, the dislocation model clarifies some aspects of migration, termination, and modification. In their model for kinking in zinc single crystals, Hess and Barrett (1949, p. 603) proposed that KB boundaries are zones of aligned dislocations of the same sign which become localized after translation gliding. Boundary migration in stibnite may be viewed as the movement of a dislocation array, which is much more complicated than simple dislocation motion. The dislocation array ceases to migrate when the bond energy between the $\mathrm{Sb}$ and $\mathrm{S}$ atoms exceeds the maximum resolved shear stress on the slip planes. An array of dislocations is a zone of weakness in the crystal due to structural misfits, which is why fractures follow DB boundaries during the modification stage.

DB boundaries have a finite width. Boundaries measured from the SEM photomicrographs of stibnite are $1-3 \mu \mathrm{m}$ in width (Fig. 3G). This observation agrees with the reported $\mathrm{KB}$ boundary width of $1-2 \mu \mathrm{m}$ in biotite, inferred from their optical behavior under a polarizing microscope (Etheridge et al., 1973, p. 32). When dislocation pileups are envisioned over a zone $1 \mu \mathrm{m}(10,000 \AA)$ wide, where the individual zones of dislocations are only tens of Angstroms wide, the DB boundary becomes too complex to be modelled simply.

\section{Comparison with other microstructure studies}

In contrast to Hess and Barrett's (1949, p. 601) suggestion that the rotated segment of a kink is consistently curved, we observed them to be straight planes (Figs. 5A and 7A). Klassen-Neklyudova's (1964, pp. 134135) shock-induced deformation experiments with CsI and naphthalene single crystals produced kinematics similar to stibnite. KB formation was preceded by extensive plastic deformation, a sudden stress redistribution, then boundary migration much slower than initiation. The modelling work on flexural-slip folding by Weiss (1969) produced geometries of single and wedge kink bands analogous to those in stibnite. Paterson and Weiss (1966, p. 369) present the idea that chevron folds in phyllite develop through intersections of conjugate $\mathrm{KBs}$. This has not been the case in stibnite, where chevron DBs initiated independently of any conjugate KBs. Our experimental work does not substantiate Starkey's (1968) hypothesis that unit cell dimensions determine a mineral's maximum kink angle. 


\section{Textures of naturally deformed stibnite}

The "wedge-shaped features" and "crumpled lamellar texture" noted in naturally deformed stibnites are concluded to be DBs, rather than deformation twins. The rather ill-defined "wedge-shaped features" of the ore texture literature have been recognized by this study to be one of the following: (1) wedge $\mathrm{KBs}$ (Compare Fig. $5 \mathrm{C}$ and $5 \mathrm{G}$.); (2) serrated KBs; or (3) a geometrical form developed from the meeting of other types of DBs, such as the single $\mathrm{PB}$ and single $\mathrm{KB}$, documented in Fig. 7G,H. The "crumpled lamellar texture" is probably indicative of chevron PB formation.

Naturally deformed stibnites from La Tarnia, Spain, and Stibnite Hill, Montana, contain microstructures of the same geometry as those deformed experimentally. In these natural materials, wedge KBs, chevron PBs, and serrated KBs were the most common, while the other types were rare. The higher confining pressures in the environment of the naturally deformed stibnites are suggested as the explanation for this frequency distribution. This is supported by our MSSD experiments, where chevron and serrated types were always associated with higher confinement and higher stresses. Most naturally deformed DB boundaries are bent. The stibnite experiments have shown that this bending is a modification of initially straight DB boundaries. From other localities, such as Iyo in Japan, single KBs were observed in deformed single crystals from vugs, which are low confinement natural environments. In agreement with this, single KBs were observed to develop experimentally in areas of low confinement. Two generations of DBs have been noted in some natural stibnites (Fig. 5G).

Ypma $(1975$, p. 205) has noted annealed deformation bands in the stibnite ores of the Murchison Range, Transvaal. He notes "numerous bands almost perpendicular to c", which in our terminology would be the chevron PBs. In addition, stibnite from the Gravelotte mine has DBs, "generally annealed into a scalloped flat grain assemblage, with numerous small subgrains". We have noted an identical texture from the Stibnite Hill, Montana, stibnite locality (Fig. $5 \mathrm{H}$ ). These textures are consistently associated with high temperature annealing (Clark et al., 1977). Since DB boundaries in our room-temperature experiments were straight during initiation, migration, and termination, we interpret "scalloped DB boundary textures" as a product of subsequent annealing in stibnite as well.

\section{CONCLUSIONS}

In contrast to the terminology used in the literature, the microstructures in stibnite are deformation bands, not deformation twins. The deformation bands are produced by activation of translation gliding along the $(010)$ [001] slip system. A series of deformation experiments on the microscope stage produced a variety of deformation band types in stibnite which we subdivide into two basic subsets: (1) true kink bands, with $\phi$ angles averaging 
around $70^{\circ}$ and (2) perpendicular bands, more closely related to a chevron fold geometry, with $\phi$ angles of approximately $90^{\circ}$. Our experimental results suggest that kink bands develop under lower confining pressure than do the higher angle perpendicular bands. Theoretical support for this observation was found by analogy with Ramsay's shear strain calculations for kink and chevron folds in rocks. The geometry of deformation bands in minerals and rocks might be a useful indicator of the amount of confinement and stress active during their formation.

Our observations on DB formation in stibnite suggest a general model for deformation banding in minerals. The four stages recognized experimentally are initiation, migration, termination, and modification. The early initiation stage is perhaps the most important in determining the type of $\mathrm{DB}$ to be formed. Initiation should be preceded by gentle folding, slip, and/or, cleavage dilation. The location of DB initiation within the crystal is a function of the local stress distribution which is in turn controlled by experimental design, surface imperfections, nature of local confinement, and other deformation features. As a particular band initiates, the longitudinal propagation (lengthening) is consistently much more rapid than subsequent migration (widening). Migration of DB boundaries may be envisioned to occur in two stages: (1) initial lateral migration when the crystal structure is first deflected and (2) partial locking of the DB as shear-strain increments on the slip plane in the band increase. If stresses build up past this threshold, a type of modification occurs involving a band width reduction to the final "lockup" configuration. Not all experimentally produced DBs experienced all stages. Two exceptions were rapid rotation of the slip plane past the critical angle for migration and termination of the run while the band was in a locked stage. The initiation and migration stages terminate either at the end of continuous crystal structure or because of changes in the stress-strain regime within the specimen. Termination produced characteristic triangular cleavage pits in stibnite. Theoretically, these should be seen whenever the wedge kink-band geometry is produced. Subsequent bending of initially straight DB boundaries may occur.

The basic stibnite deformation-band geometries and kinematics also apply to other ductile sulfides as well. While stibnite was the main object of this research, molybdenite $\left(\mathrm{MoS}_{2}\right)$ (Fig. $3 \mathrm{H}$ ) and covellite (CuS) were also experimentally deformed. The kinematic observations in stibnite should serve as a general model for deformation banding in silicate and sulfide minerals. The technique of television photomicroscopy, combined with a microscope stage strain device, holds promise in the study of other types of minerals and microstructures, because of its unique ability to capture the kinematic history. 


\section{ACKNOWLEDGEMENTS}

We wish to thank Ms. Ksuzsanna Molnar and her associates at the LSA Media Center of the University of Michigan for their cooperation in the use of video tape recorders and editing facilities. Mr. R.R. Thalner and Mr. Karl Couyomjian of Thalner Electronics Laboratories, Inc. were very kind in lending specialized camera and video-tape equipment for use in this research. Invaluable technical advice was given by $\mathrm{Mr}$. John Cannell and $\mathrm{Mr}$. Jon Niemczak of the University of Michigan Television Center. Thanks are also due to the staff of the scanning electron microscope laboratory, Department of Materials and Metallurgy at the University of Michigan, for technical advice and instruction. Dr. D.R. Peacor offered helpful advice about documenting the slip system of stibnite. Mr. Earl Detra provided stibnite speciment from Stibnite Hill, Montana. Mr. James Hinchcliff gave much advice on sample preparation. Mr. Derwin Bell artistically drafted all the diagrams. Ms. J.A. Konnert and Dr. H.T. Evans, Jr., of the U.S. Geological Survey, graciously produced several rough drafts of the crystal structure diagram as a test of a newly compiled version of the ORTEP program (Johnson, 1965). The manuscript has benefited from the review of Dr. Michael Foose.

This research has been supported by grants from the following organizations: (1) The Geological Society of America (Research Grant 2225-77); (2) The Scott Turner Memorial Fund of the University of Michigan; and (3) Sigma Xi, the Scientific Research Society of North America. McQueen received support as a National Science Foundation Graduate Fellow at the University of Michigan during the period of this study.

We also wish to thank Shirley D. McQueen for editing and typing of rough drafts.

\section{REFERENCES}

Anderson, T.B., 1974. The relationship between kink bands and shear fractures in the experimental deformation of slate. J. Geol. Soc. London, 130: 367-382.

Baer, A.J, and Norris, D.K. (Editors), 1969. Proceedings, Conference on Research in Tectonics (Kink Bands and Brittle Deformation). Geol. Surv. Can. Pap., 68-52, 373 pp.

Bayliss, P. and Nowacki, W., 1972. Refinement of the crystal structure of stibnite. $Z$. Kristallogr., 135: 308-315.

Bhattacharya, D.S., 1977. Geometry of kink bands - a theoretical analysis. Am. J. Sci., 277: 503-508.

Buerger, J.J., 1930. Translation-gliding in crystals. Am. Mineral., 15: 45-64.

Cameron, E.N., 1961. Ore Microscopy. John Wiley, New York, N.Y., 293 pp.

Clark, B.R. and Kelly, W.C., 1976. Experimental deformation of common sulphide minerals. In: R.G.J. Strens (Editor), Physics and Chemistry of Minerals and Rocks. John Wiley, New York, N.Y. pp. 51-69.

Clark, B.R., Price, F.R. and Kelly, W.C., 1977. Effects of annealing on deformation textures in galena. Contrib. Mineral. Petrol., 64: 149165.

Donath, F.A., 1969. Experimental study of kink band development in strongly anisotropic rock. In: A.J. Baer and D.K. Norris (Editors), Proceedings, Conference on 
Research in Tectonics (Kink Bands and Brittle Deformation). Geol. Surv. Can. Pap., 68-52: 255-287.

Etheridge, M.A., Hobbs, B.E. and Paterson, M.S., 1973. Experimental deformation of single crystals of biotite. Contrib. Mineral. Petrol., 38: 21-36.

Gilman, J., 1954. Mechanism of ortho kink-band formation in compressed zinc monocrystals. J. Metals, 6: 621-629.

Hess, J.B. and Barrett, C.S., 1949. Structure and nature of kink bands in zinc. Trans. Am. Inst. Min. Metall. Eng., 185: 599-605.

Hobbs, B.E., Means, W.D. and Williams, P.F., 1976. An Outline of Structural Geology. John Wiley, New York, N.Y, 571 pp.

Hofmann, W., 1933. Die Struktur der Minerale der Antimonitgruppe [The structure of the minerals of the stibnite group]. Z. Kristallogr., 86: 225-245.

Johnson, C.K., 1965. ORTEP: A Fortran Thermal-ellipsoid Plot Program for Crystal Structure Illustration. Oak Ridge National Lab., ORNL 3794, revised, $135 \mathrm{pp}$.

Klassen-Neklyudova, M.V., 1964. Mechanical Twinning of Crystals. Consultants Bureau, New York, N.Y., 276 pp.

Means, W.D., 1977. A deformation experiment in transmitted light. Earth Planet. Sci. Lett., 35: 169-179.

Mügge, O., 1898. Ueber Translationen und verwandte Erscheinungen in Krystallen [ On translation and related phenomena in crystals]. Neues Jahrb. Mineral. Geol. Palaeontol. Jahrg. 1898, 1: 71-186.

Orowan, E., 1942. A type of plastic deformation new in metals. Nature, 149: 643-644.

Palache, C., Berman, H. and Frondel, C., 1944. Dana's System of Mineralogy, Vol. 1. John Wiley, New York, N.Y., 7 th ed, 834 pp.

Paterson, M.S. and Weiss, L.E., 1966. Experimental deformation and folding in phyllite. Bull. Geol. Soc. Am., 77: 343-374.

Ramdohr, P., 1969. Ore Minerals and Their Intergrowths, Pergamon Press, London, (English translation) $1174 \mathrm{pp}$.

Ramsay, J.G., 1967. Folding and Fracturing of Rocks. McGraw-Hill, New York, N.Y., $568 \mathrm{pp}$.

Reed-Hill, R.E., 1973. Physical Metallurgy Principles. D. Van Nostrand Company, New York, N.Y., 2nd ed., 919 pp.

Rondeel, H.E., 1969. On the nucleation of kink bands. In: A.J. Baer and D.K. Norris (Editors), Proceedings, Conference on Research in Tectonics (Kink Bands and Brittle Deformation). Geol. Surv. Can. Pap., 68-52: 363-365.

Salmon, B.C., Clark, B.R. and Kelly, W.C., 1974. Sulfide deformation studies: II. Experimental deformation of galena to 2000 bars and $400^{\circ} \mathrm{C}$. Econ. Geol., 69: 1-16.

Scavnicar, S., 1960. The crystal structure of stibnite. A redetermination of atomic positions. Z. Kristallogr., 114: 85-97.

Stanton, R.L., 1972. Ore Petrology. McGraw-Hill, New York, N.Y., 713 pp.

Starkey, J., 1968. The geometry of kink bands in crystals - a simple model. Contrib. Mineral. Petrol., 19: 133-141.

Weiss, L.E., 1969. Flexural slip of foliated model materials. In: A.J. Baer and D.K. Norris (Editors), Proceedings, Conference on Research in Tectonics (Kink Bands and Brittle Deformation). Geol. Surv. Can. Pap., 68-52: 294-357.

Weiss, L.E., 1972. The Minor Structures of Deformed Rocks: A Photographic Atlas. Springer-Verlag, New York, N.Y.

Ypma, P.J.M., 1975. Fabrics of deformed massive sulfide deposits. In: Abstracts of Papers, XVI Geokongres 75 (Mineralization in Metamorphic Terraines). Geol. Soc. S. Afr. pp. 204-207. 